\title{
New frontiers in ground, essence, and modality: introduction
}

\section{Donnchadh Ó Conaill ${ }^{1}$ - Tuomas Tahko²}

Published online: 17 December 2018

(c) Springer Nature B.V. 2018

Ground, essence, and modality seem to have something to do with each other. Can we provide unified foundations for ground and essence, or should we treat each as primitives? Can modality be grounded in essence, or should essence be expressed in terms of modality? Does grounding entail necessitation? Are the notions of ground and essence univocal? This volume focuses on the links - or lack thereof-between these three notions, as well as the foundations of ground, essence, and modality more generally, bringing together work on the metaphysics, epistemology, and logic of these three notions by some of the leading figures in the field as well as emerging young scholars.

The invited contributors to this volume presented their work at a conference on Ground, Essence, and Modality at the University of Helsinki in June 2016, funded by the Academy of Finland Project The Epistemology of Metaphysics: From Rationalism to Nominalism. This conference is just one of many recent high-profile events and publications on these themes (e.g., the edited volumes Correia and Schnieder 2012a; Sirkel and Tahko 2014; Jago 2016).

After providing a brief historical summary of the (re)emergence of modality, essence and ground as central notions in metaphysics (Sect. 1), we shall outline some of the main themes in recent work on these notions and on the links between them (Sect. 2). In Sect. 3 we briefly introduce the papers in this volume.

\section{Historical background}

The story of modality in the last century is a familiar one. For several decades modal discourse was shunned as suspiciously intensional or lacking empirical bona fides.

\footnotetext{
$凶$ Donnchadh Ó Conaill doconaill@yahoo.co.uk

$\bowtie$ Tuomas Tahko tuomas.tahko@bristol.ac.uk

1 Université de Fribourg, Fribourg, Switzerland

2 University of Bristol, Bristol, UK
} 
Pioneering work by Saul Kripke and Ruth Barcan Marcus on quantified modal logic (e.g., Kripke 1963; Marcus 1967) reintroduced modality to philosophically polite society. The 1970s and 1980s saw a tide of work both on and using modality, with debates on the nature of possible worlds (Plantinga 1974; Lewis 1986), de re modal claims (Kripke 1980), natural kind terms and semantic externalism (Putnam 1975), characterisations of physicalism and rival positions in the philosophy of mind (Davidson 1970), and moral realism and rival positions in metaethics (Railton 1986).

Impressive though this body of work was, doubts began to surface as to whether modal notions were capable of delivering all that had been promised on their behalf. One set of doubts concerned the explanatory role which had fallen to a specific modal notion, supervenience. Jaegwon Kim suggested:

Supervenience itself is not an explanatory relation. It is not a 'deep' metaphysical relation; rather, it is a 'surface' relation that reports a pattern of property covariation, suggesting the presence of an interesting dependency relation that might explain it (1993, p. 167).

Similarly, Terry Horgan wrote "The moral is not that supervenience cannot be an important part of a broadly materialistic metaphysics, but rather this: putative supervenience relations that are themselves unexplainable and sui generis cannot play such a role" (1993, pp. 565-566). What is needed, he continued, is a notion of "ontological supervenience that is robustly explainable in a materialistically explainable way" (op. cit., p. 566).

These observations can be seen as clearing the way for the introduction of specifically explanatory notions, ones which do not just report modal co-variation between, e.g., phenomenal and physical facts or moral and non-moral properties, but which are apt to explain these co-variations. The notion which has proved by far the most popular is that of metaphysical ground (or grounding). This is frequently introduced with reference to explanatory questions (Schaffer 2009, p. 375; Raven 2015, p. 323) or purported non-causal explanations (Rosen 2010, pp. 110-111; Audi 2012, pp. 689-690). Indeed, ground is sometimes introduced as suitable to answer questions for which modal notions cannot suffice (e.g., Rosen 2010, p. 114; Fine 2012, p. 38, pp. 41-42). ${ }^{1}$

Other doubts about modal notions began to surface around the same time. Some of these were also couched as requests for explanation which modal notions could not deliver. E. J. Lowe noted that the intuitive notion of ontological dependence was explanatory and not just modal:

there is a strong intuition that [...] Socrates's life is the truly dependent entity here, while Socrates is a wholly independent existent (a substance). We want to say that Socrates's life only exists because Socrates does, whereas it would be putting the cart before the horse to say that Socrates exists because his life does (1994, p. 39).

Lowe's own suggestion to meet this explanatory demand was to appeal to identity dependence, where

\footnotetext{
1 For a more detailed historical overview of ground see Correia and Schnieder (2012b, § 2). In what follows we shall treat ground as a relation which holds between facts, though there are conceptions of ground which treat it as holding between non-factual entities (e.g., Schaffer 2009).
} 
To say that the identity of $x$ depends on the identity of $y$ - or, more briefly, that $x$ depends for its identity upon $y$ - is just to say that which thing of its kind $x$ is is [logically or metaphysically] fixed (at least partially) by which thing of its kind $y$ is (op. cit., p. 41).

The notion of identity which is to be determined here is not that of mere self-identity (indeed, it is difficult to see how the identity of any entity $x$ with itself could be determined in any substantive sense, either by some other relation $x$ bears to itself or by any relation $x$ bears to any other entity $y$ ). Rather, what is to be determined is identity in the sense of there being a fact of the matter as to which entity of its type $x$ is. For instance, there is a fact of the matter as to which event is the assassination of Julius Caesar, a fact which is determined in part by the identity of the person assassinated (see also Tahko and Lowe 2015, § 4.2).

A substantive notion of identity was further exploited in work by Kit Fine. The modal renaissance of the late twentieth century had made much of essential properties, typically understood in terms of de re modal properties (Marcus 1967; Kripke 1980). In a series of papers beginning with the classic 'Essence and Modality', Fine challenged this understanding of essence. Fine introduced a battery of familiar examples, all of which can be seen as supporting the following conclusion:

any essentialist attribution will give rise to a necessary truth [...] However, the resulting necessary truth is not necessary simpliciter. For it is true in virtue of the identity of the objects in question; the necessity has its source in those objects which are the subject of the underlying essentialist claim (1994, pp. 8-9).

The notion of 'identity' to which Fine appeals is not the same as Lowe's. Indeed, it is not entirely clear what he means by this term, particularly since he denies that the operator 'it is true in virtue of the identity of $x$ ' can be analysed "into the notions of the identity of an object and of a proposition being true in virtue of the identity of an object" (1995a, p. 273). Rather,

The notation should be taken to indicate an unanalyzed relation between an object and a proposition. Thus we should understand the identity or being of the object in terms of the propositions rendered true by its identity rather than the other way round (op. cit.; see also 1995b, p. 69 n2).

Methodologically, this feels like putting the cart before the horse. Consider Fine's most famous example, that of Socrates and his singleton set. According to a modal criterion of essence, Socrates essentially belongs to his singleton:

But, intuitively, this is not so. It is no part of the essence of Socrates to belong to the singleton. [...] There is nothing in the nature of a person, if I may put it this way, which demands that he belongs to this or that set or which demands, given that the person exists, that there even be any sets (1994, pp. 4-5).

For this example to be convincing, we must surely understand the essence or nature of Socrates independently of understanding the proposition which we are evaluating (e.g., the proposition that Socrates essentially belongs to his singleton). And the same presumably goes for any proposition which is supposedly true in virtue of the identity or 
being of Socrates. Indeed, it looks as though we can only understand some proposition as true in virtue of the identity of Socrates by having some prior understanding of his identity, thus turning Fine's suggested procedure on its head.

Nevertheless, Fine's basic point has been widely accepted: there is a notion of essence, that of the being or identity of an object or objects, which cannot be captured in purely modal terms. Indeed, Fine suggests that

far from viewing essence as a special case of metaphysical necessity, we should view metaphysical necessity as a special case of essence. [...] The metaphysically necessary truths can $[\ldots]$ be identified with the propositions which are true in virtue of the nature of all objects whatsoever (1994, p. 9).

At the turn of century, modality had regained a central place in metaphysics and undergone 30 years of sustained work. Partly as a result of this work and partly as a result of its perceived limitations, two non-modal notions stood ready to be developed: essence and metaphysical ground. Each was in some sense more fine-grained than modal notions, each was connected with projects of explaining modal truths, and each promised new advances across a range of philosophical disciplines.

\section{Recent themes}

Work on modality has continued apace in the early years of the twenty-first century, while essence and ground have each developed flourishing research programmes of their own. In this section we shall briefly sketch some of the main themes informing work on each of these notions, paying special attention to work on the links between them.

One recent theme in work on modality has been the development of new metaphysical theories of modality, which offer alternatives to the well-established models of possible worlds. For instance, the "new actualists" seek to account for modality without also having to account for possible worlds (Vetter 2011, p. 742). Two versions of new actualism have been particularly prominent. Dispositionalism seeks to locate metaphysical modality in the dispositional properties of actually existing entities (Borghini and Williams 2008; Jacobs 2010; Vetter 2015). Essentialism, developing a suggestion which as we saw was made in Fine 1994, seeks to locate metaphysical modality in the essences of actually existing entities (Oderberg 2007; Jubien 2009; Lowe 2012a; Hale 2013). ${ }^{2}$ Essentialism in this sense is thus one of main ways in which the notion of essence has been developed; we shall consider some others presently.

Another major theme in work on modality concerns our knowledge of what is metaphysically possible or necessary. The traditionally dominant view held that this knowledge is a priori: for instance, conceivability (see, e.g., the papers in Gendler and Hawthorne 2002) and intuition (Bealer 2000) have been put forward as ways of

\footnotetext{
2 It is also worth noting that essentialism and dispositionalism can both be expressed in terms of what grounds metaphysical modality. For example, Lowe suggests that "a metaphysically necessary truth is a truth which is either an essential truth or else a truth that obtains in virtue of the essences of two or more distinct things. On this account, all metaphysical necessity (and by the same token all metaphysical possibility) is grounded in essence" (2012a, p. 939).
} 
knowing modal truths. More recently there has been increasing interest in a posteriori ways of coming to know modal truths (see Fischer and Leon 2017). These approaches are collectively known as modal empiricism, as against the more traditional modal rationalism. By and large, modal empiricism tends to be somewhat skeptical about 'extraordinary' modal truths, that is, modal truths that are not ordinary in the sense that we would commonly make them outside philosophy (or science) (compare van Inwagen 1998). These will likely include at least claims about what is nomologically impossible but metaphysically possible.

As mentioned above, a flourishing research programme seeks to find the metaphysical source of modality in essences. However, there have also been critical responses both to this programme and to Fine's original suggestion that essence cannot be reduced to modality. In particular, it has been argued that Fine's examples, such as that of Socrates and his singleton, can be understood as modal truths provided that suitable adjustments or restrictions are made to the latter (see, e.g., Zalta 2006; Correia 2012; Cowling 2013; Wildman 2013; for criticism see Skiles 2015).

The broadly Finean notion of essence (and related notions such as Lowe's identity dependence) has been put to work in various areas of philosophy, such as the following: in characterizing and critically discussing ontic structural realism (Wolff 2012; French 2014; McKenzie 2014; Ó Conaill 2014) and mathematical structuralism (Linnebo 2008); in arguments against priority monism (Lowe 2012b; Tallant 2015); and in discussions of revelation, the thesis that we can come to know the essence of phenomenal properties by attending to our own experiences (Goff 2015; Trogdon 2017). One of the most prominent applications of essence has been in the literature on ground. A number of theorists have suggested that for grounding to occur, there must be an essential connection between the grounded fact and its grounds (Rosen 2010; Audi 2012; Ó Conaill 2018). Other theorists have considered the possibility of explaining or even reducing ground to essential connections (Correia 2013; Fine 2015).

The literature on ground has seen more work on its formal features than has been the case with recent literature on essence. The standard view is that ground is an irreflexive, asymmetric and transitive relation, but each component of this view has been questioned or denied. ${ }^{3}$ For instance, all three of these formal features have been denied by Gonzalo Rodriguez-Pereyra (2015); for a defence of all three see Raven (2013). Further challenges have been raised to irreflexivity (Jenkins 2011), transitivity (Schaffer 2012; Tahko 2013), and asymmetry (Thompson 2016).

A closely-related issue is whether chains of grounds must be well-founded. There has been some debate in the literature as to how this notion should be understood, but a recent consensus has begun to form around the view that for a grounding chain to be well-founded is for every grounded fact in the chain to be fully grounded by facts which themselves do not require any grounds (see Dixon 2016, p. 446; Rabin and Rabern 2016, p. 366; for a related claim see Litland 2016). Early work on ground tended to assume without much argument that chains of ground must be well-founded (e.g., Schaffer 2010, p. 37), but this assumption has come under increasing criticism (Bliss 2013; Morganti 2015; Tahko 2014, and the papers in Bliss and Priest 2018).

\footnotetext{
${ }^{3}$ Ground is typically also taken to be non-monotonic and factive, but these features are rarely challenged.
} 
Note also the connection between this topic and the formal features of ground: if instances of ground can be, for example, symmetrical, then this removes an obvious objection to non-well-founded grounding chains.

The well-foundedness of grounding chains is also closely related to two other issues. The first is that of fundamentality (or foundationalism - though on the difference between these notions see, e.g., Raven 2016). It is often assumed that the grounds of a fact are metaphysically prior to or more fundamental than the grounded fact. Thus, ground seems to provide a way to understand relative fundamentality, at least between facts which stand in grounding relations to each other. And it is tempting to think that facts which are ungrounded are absolutely fundamental; they are such that no facts are more fundamental. Furthermore, one might think that the ungrounded facts serve as a complete minimal basis for all the facts they ground. Whether these notions of fundamentality can be defined in terms of ground, and how they relate to other notions of fundamentality, are discussed by Karen Bennett (2017) and Tuomas Tahko (2018).

The second issue is the question of what, if anything, grounds the grounding facts: that is, what explains the fact that a certain fact, [f], is grounded in facts [g1], [g2], etc.? This has been presented as a potentially devastating problem for grounding, because it threatens to erase the difference between more and less fundamental facts (Sider 2011). Responses which have been offered include: (a) the grounds, i.e., [g1], [g2], etc., themselves ground the fact that they ground [f] (Bennett 2011; deRosset 2013); (b) the fact that [f] is grounded in facts [g1], [g2], etc. is itself grounded in essential facts concerning the nature of [f] or its grounds, or perhaps their constituents (Rosen 2010; Fine 2012); (c) the fact that [f] is grounded in facts [g1], [g2], etc. is not itself apt to be grounded-rather, it is autonomous (Dasgupta 2014).

As mentioned earlier, work on the relations between ground and essence has flourished. Another lively set of discussions concerns the relations between ground and metaphysical modality (specifically necessity). For instance, it is widely assumed that the full grounds of a fact metaphysically necessitate that the grounded fact obtains; ${ }^{4}$ this view has been termed necessitarianism. Necessitarianism has come under fire (Leuenberger 2014a; Skiles 2015), as has the related thesis that grounded facts supervene on their grounds (Leuenberger 2014b). More generally, the question of how ground relates to ontological dependence remains a live issue. Early discussions of ground tended to run these notions together (Schaffer 2009; Rosen 2010). More recently a range of options for relating these notions has been considered by Benjamin Schnieder (2017; see also Raven 2016).

The range of applications of ground is far too broad to adequately cover here. A very brief summary would include formulating physicalism (Block 2015; Ney 2016; Schaffer 2017; Ó Conaill 2018; Wilson 2018); formulating and accounting for the causal closure of the physical (Tiehen 2015; Kroedel and Schulz 2016); and formulating and discussing various positions in metaethics (Väyrynen 2013; Bader 2017; Leary 2017; Toppinen 2018).

\footnotetext{
$\overline{{ }^{4} \text { On the distinction between full }}$ and partial grounds see Fine (2012, p. 50).
} 


\section{The papers in this special issue}

The special issue opens with half a dozen papers on ground, its relation to other notions, and its applications. In these papers we will see that there is also a need to reconsider the notions of ontological dependence, essence, and modality. The half a dozen papers in the second half of the special issue deal precisely with these topics. In what follows we shall briefly outline the main theses of each paper.

Henrik Rydéhn's paper Grounding and Ontological Dependence explores how different notions of ontological dependence and ground relate to each other. He begins with the assumption that ground is factive: if [f] is grounded in [g], then [f] and [g] both exist. He argues that on this conception, ground neither requires nor necessitates any form of rigid ontological dependence (where the grounded fact cannot obtain unless the specific facts which ground it obtain). Nor is rigid dependence necessary for nonfactive grounding; but at least one version of rigid dependence (Lowe's explanatory existential dependence) is sufficient for non-factive grounding. Rydéhn then considers generic ontological dependence (where the grounded fact cannot obtain unless some fact or facts of a certain type obtain). He argues that given the Principle of Metaphysical Insufficiency (roughly, if [f] is factively grounded at some possible world, it is factively grounded at every world in which it obtains), then generic dependence is necessary (but insufficient) for both factive and non-factive grounding.

In The Ground of Ground, Essence, and Explanation, Michael Wallner deals with one of the most pressing questions for a theory of ground, namely, the problem of what grounds the grounding facts, as discussed in Sect. 2 above. Wallner surveys some of the answers that have been offered so far, by Bennett, deRosset, and Litland. The main claim of his paper is that if grounding is to be regarded as a type of metaphysical explanation (as opposed to just something that backs metaphysical explanation), then Grounding Essentialism is the most promising strategy. This type of strategy suggests that the grounding facts are grounded in the essences of either the grounds or the grounded facts. Such a strategy has been outlined in previous work by Rosen (2010), Fine (2012), and Dasgupta (2014), but Wallner goes on to develop a more systematic approach on these lines and connects the issue to other areas of interest for the grounding theorist.

In the previous section we mentioned that ground may be one way to understand the relative fundamentality of facts, i.e., one fact's being more fundamental than another. In The Logic of Relative Fundamentality, Fabrice Correia objects to any such account. Having outlined a detailed logic of relative fundamentality, he then explores the Reductive View on which for a fact to be grounded can be analysed in terms of relative fundamentality. Specifically, Correia shows how the proposed logic of relative fundamentality allows us to derive important principles which feature in different logical schemes for ground.

Another topic mentioned in the previous section was whether or not grounding chains must be well-founded. Michele Lubrano, in his paper The Emergence of Ground: Some Limitative Results tackles this issue. He discusses a recent argument that grounding chains need not be well-founded, provided by Matteo Morganti (2015), who argues that in an infinitely long grounding chain the obtaining of a grounded fact is not something passed up to this fact from its immediate grounds (the transmis- 
sion model), but comes from the infinite chain of grounds as a whole (the emergence model). Morganti defends this claim by adopting an argument originally developed by Jeanna Peijnenburg and David Atkinson in defence of epistemological infinitism (2013). Lubrano argues that Peijnenburg and Atkinson's argument cannot be applied successfully to some prominent versions of ground.

Samuele Chilovi's paper Grounding Entails Supervenience addresses a number of arguments advanced by Stephan Leuenberger (2014b) against the suggestion that grounded facts supervene on their grounds (or on facts of the type to which their grounds belong). Chilovi's strategy is to accept Leuenberger's arguments against four different principles linking grounding and supervenience, but by working through these arguments to arrive at a further principle which does not succumb to any of Leuenberger's objections. Specifically, Chilovi argues that a grounded fact must supervene on a certain plurality of types of fact. In this way, he suggests, we can capture how grounded facts are modally sensitive to the types of facts to which their actual grounds belong.

Benjamin Schnieder's On Ground and Consequence is an example of the notion of ground being used to supplement a modal understanding of some concept, in this case the concept of logical consequence. Schnieder argues that the modal understanding of logical consequence generates counterexamples and fails to locate the source of the truth of the consequent. He then outlines an account of logical consequence in terms of ground, and compares his account to different relevance logics.

Barbara Vetter defends dispositionalism about modality against a criticism by David Yates (2015) that it cannot capture certain formal conditions on any account of modality. The worry is that dispositions, as usually understood, can only bring about certain contingent events or states; on this view there is no disposition to bring it about that $2+2=4$. In A Plenitude of Powers, Vetter responds by arguing that there are such dispositions. She defends the view that positing dispositions for necessary truths or states is not ad hoc, by arguing that they can be understood as combinations of other features which have been ascribed to dispositions (e.g., that certain dispositions are necessarily always manifested, or that they can manifest without partners or stimulus conditions). She also argues that these dispositions will be borne by specific objects, e.g., whatever is the truthmaker for the truth that $2+2=4$.

In Two Notions of Metaphysical Modality, Antonella Mallozzi tackles an important issue in modal epistemology: the issue of whether there is just one modal space or modal primitive (modal monism) or whether metaphysical modality and conceptual modality are genuinely distinct. Mallozzi draws a contrast between David Chalmers's project, which operates within the realm of modal monism and employs two-dimensional modal semantics to account for a posteriori necessities, and the traditional Kripkean approach, whereby the underlying ground of metaphysical necessities lies in the essences of things. Mallozzi identifies an inconsistent triad between three theses (modal monism, two-dimensionalism, and metaphysical Kripkeanism), and argues that, ultimately, Chalmers's conceivability-based strategy is probably going to be unsatisfactory from the Kripkean perspective, since by starting from a conceptualcum-epistemic approach, the conceivability-based strategy fails to do justice to the modal metaphysics that underlies metaphysical Kripkeanism. 
In The Difference Between Epistemic and Metaphysical Necessity, Martin Glazier engages in further examination of the modal space and the important distinction between alethic, objective, or genuine necessities, such as metaphysical and natural necessity, and subjective necessities such as epistemic or deontic necessity. However, distinguishing between these types of necessity, important though it is, is quite difficult. Glazier attempts to give an account of genuine necessity in explanatory terms. He first rules out various unsatisfactory accounts for dealing with genuine necessity, before developing his own approach. Glazier's paper ties the themes of this volume together in an interesting manner, as he discusses whether the relevant type of explanation at hand here could be grounding explanation, even though he ultimately rejects this idea. Instead, he argues that to be genuinely necessary is just to impose constraints on the world which have explanatory power-this amounts to what Glazier calls necessitarian explanation.

Penelope Mackie considers the issue of de re modal claims, particularly those concerning the persistence conditions of objects. For instance, a statue is widely thought to have different persistence conditions to the lump of material from which it is formed. Contingent identity theorists argue that despite this, the statue is identical with the lump. They seek to accommodate the difference in persistence conditions by claiming that modal predicates are 'Abelardian': they can stand for different properties depending on the context, e.g., on the subject term to which they are attached. In Persistence and Modality, Mackie argues against this construal of modal predicates; specifically, she claims that if de re modal predications are understood in this way, they can be satisfied too easily, which defeats the purpose of making de re as opposed to de dicto modal predications.

Mark Jago's Essential Bundle Theory and Modality also considers contingent identity, but in a more sympathetic manner. Bundle theories identify concrete objects with bundles of properties, but in so doing they face problems accommodating the contingent properties of concrete objects. Jago proposes essential bundle theory, which identifies concrete objects with bundles of essential properties. This proposal faces a variant of the problem of contingent properties: it seems that on this proposal, each concrete object is necessarily located wherever it exists in time and space. Jago argues that this problem can be met by adopting an essential property version of counterpart theory, on which the counterpart relation is the same-essence relation. This version of counterpart theory allows for contingent identity, and so allows for each concrete object to possibly have existed elsewhere in space and time (because it could have been identical with some other bundle of essential properties than the bundle with which it is actually identical).

In Taking Leave of Our Essences, Nathan Wildman examines the very widely accepted Finean idea that metaphysical modality reduces to essence. Wildman questions this common idea by way of introducing four puzzles that pose difficult challenges for those who wish to reduce metaphysical modality to essence. The first puzzle suggests that there are cases where some proposition is true in virtue of the essence of some entities, but where that proposition is not in fact metaphysically necessary. The second puzzle concerns essences that themselves feature modal truths (loaded essences), such as potentialities contained within an essence. The third puzzle, the Isolation puzzle, examines the intuitive idea that possibilities involving only the intrinsic properties of 
an entity should only be sensitive to the essence of the entity itself and the essences of the relevant intrinsic properties. Finally, the fourth puzzle, named after Columbo, suggests that there is a tension regarding the independently plausible claims that there is a universal plurality, a collective essence of that plurality (collective essence of absolutely everything), and the principle that some entity possibly exists if and only if the entity's existence is not excluded by the collective essence of the universal plurality. In each of these four cases, Wildman anticipates some trouble for the essentialist. He concludes by briefly considering where these puzzles leave us with regard to the relationship between essence and modality.

Acknowledgements Research related to this volume and the conference preceding it were supported by Academy of Finland Grants Nos. 266256 and 274715.

\section{References}

Audi, P. (2012). Grounding: Toward a theory of the in-virtue-of relation. Journal of Philosophy, 109(12), 685-711.

Bader, R. (2017). The grounding argument against non-reductive moral realism. In R. Shafer-Landau (Ed.), Oxford studies in metaethics 12 (pp. 106-134). Oxford: Clarendon Press.

Bealer, G. (2000). A theory of the a priori. Pacific Philosophical Quarterly, 81(1), 1-30.

Bennett, K. (2011). By our bootstraps. Philosophical Perspectives, 25, $27-41$.

Bennett, K. (2017). Making things up. Oxford: Oxford University Press.

Bliss, R. (2013). Viciousness and the structure of reality. Philosophical Studies, 166(2), 399-418.

Bliss, R., \& Priest, G. (Eds.). (2018). Reality and its structure. Oxford: Oxford University Press.

Block, N. (2015). The Canberra plan neglects ground. In T. Horgan, M. Sabates, \& D. Sosa (Eds.), Qualia and mental causation in a physical world: Themes from the philosophy of Jaegwon Kim (pp. 105-133). Cambridge: Cambridge University Press.

Borghini, A., \& Williams, N. E. (2008). A dispositional theory of possibility. Dialectica, 62(1), 21-41.

Correia, F. (2012). On the reduction of necessity to essence. Philosophy and Phenomenological Research, 84(3), 639-653.

Correia, F. (2013). Metaphysical grounds and essence. In M. Hoeltje, B. Schnieder, \& A. Steinberg (Eds.), Varieties of dependence: Ontological dependence, grounding, supervenience, response-dependence (pp. 271-296). München: Philosophia.

Correia, F., \& Schnieder, B. (Eds.). (2012a). Metaphysical grounding: Understanding the structure of reality. Cambridge: Cambridge University Press.

Correia, F., \& Schnieder, B. (2012b). Grounding: An opinionated introduction. In F. Correia \& B. Schnieder (Eds.), Metaphysical grounding: Understanding the structure of reality (pp. 1-36). Cambridge: Cambridge University Press.

Cowling, S. (2013). The modal view of essence. Canadian Journal of Philosophy, 43(2), 248-266.

Dasgupta, S. (2014). The possibility of physicalism. Journal of Philosophy, 111(9), 557-592.

Davidson, D. (1970). Mental events. In L. Foster \& J. W. Swanson (Eds.), Essays on actions and events (pp. 207-224). Oxford: Clarendon Press.

deRosset, L. (2013). Grounding explanations. Philosophers' Imprint, 13(7), 1-26.

Dixon, T. S. (2016). What is the well-foundedness of grounding? Mind, 125(498), 439-468.

Fine, K. (1994). Essence and modality. Philosophical Perspectives, 8, 1-16.

Fine, K. (1995a). Ontological dependence. Proceedings of the Aristotelian Society, 95, 269-290.

Fine, K. (1995b). Senses of essence. In W. Sinnott-Armstrong, D. Raffman, \& N. Asher (Eds.), Modality, morality and belief: Essays in honor of Ruth Barcan Marcus (pp. 53-73). Cambridge: Cambridge University Press.

Fine, K. (2012). Guide to ground. In F. Correia \& B. Schnieder (Eds.), Metaphysical grounding: Understanding the structure of reality (pp. 37-80). Cambridge: Cambridge University Press.

Fine, K. (2015). Unified foundations for essence and ground. Journal of the American Philosophical Association, 1(2), 296-311. 
Fischer, R. W., \& Leon, F. (Eds.). (2017). Modal epistemology after rationalism. Dordrecht: Springer.

French, S. (2014). The structure of the world: Metaphysics and representation. Oxford: Oxford University Press.

Gendler, T. S., \& Hawthorne, J. (Eds.). (2002). Conceivability and possibility. Oxford: Oxford University Press.

Goff, P. (2015). Real acquaintance and physicalism. In P. Coates \& S. Coleman (Eds.), Phenomenal qualities: Sense, perception, and consciousness (pp. 121-146). Oxford: Oxford University Press.

Hale, B. (2013). Necessary beings: An essay on ontology, modality, and the relations between them. Oxford: Oxford University Press.

Horgan, T. (1993). From supervenience to superdupervenience: Meeting the demands of a material world. Mind, 102(408), 555-586.

Jacobs, J. D. (2010). A powers theory of modality: Or, how i learned to stop worrying and reject possible worlds. Philosophical Studies, 151(2), 227-248.

Jago, M. (Ed.). (2016). Reality making. Oxford: Oxford University Press.

Jenkins, C. S. (2011). Is metaphysical dependence irreflexive? The Monist, 94(2), 267-276.

Jubien, M. (2009). Possibility. Oxford: Oxford University Press.

Kim, J. (1993). Postscripts on supervenience. In J. Kim (Ed.), Supervenience and mind: Selected philosophical essays (pp. 161-174). Cambridge: Cambridge University Press.

Kripke, S. (1963). Semantical considerations on modal logic. Acta Philosophica Fennica, 16, 83-94.

Kripke, S. (1980). Naming and necessity. Cambridge: Harvard University Press.

Kroedel, T., \& Schulz, M. (2016). Grounding mental causation. Synthese, 193(6), 1909-1923.

Leary, S. (2017). Non-naturalism and normative necessities. In R. Shafer-Landau (Ed.), Oxford studies in metaethics (Vol. 12, pp. 76-105). Oxford: Clarendon Press.

Leuenberger, S. (2014a). Grounding and necessity. Inquiry, 57(2), 151-174.

Leuenberger, S. (2014b). From grounding to supervenience? Erkenntnis, 79(1), 227-240.

Lewis, D. K. (1986). On the plurality of worlds. Oxford: Blackwell.

Linnebo, O. (2008). Structuralism and the notion of dependence. The Philosophical Quarterly, 58(230), $59-79$.

Litland, J. E. (2016). An infinitely descending chain of ground without a lower bound. Philosophical Studies, 173(5), 1361-1369.

Lowe, E. J. (1994). Ontological dependency. Philosophical Papers, 23(1), 31-48.

Lowe, E. J. (2012a). What is the source of our knowledge of modal truths? Mind, 121, 919-950.

Lowe, E. J. (2012b). Against monism. In P. Goff (Ed.), Spinoza on monism (pp. 92-112). PalgraveMacmillan: Basingstoke.

Marcus, R. B. (1967). Essentialism in modal logic. Noûs, 1(1), 91-96.

McKenzie, K. (2014). Priority and particle physics: Ontic structural realism as a fundamentality thesis. British Journal for the Philosophy of Science, 65(2), 353-380.

Morganti, M. (2015). Dependence, justification and explanation: must reality be well-founded? Erkenntnis, $80(3), 555-572$.

Ney, A. (2016). Grounding in the philosophy of mind: a defence. In K. Aizawa \& C. Gillett (Eds.), Scientific composition and metaphysical ground (pp. 271-300). London: Palgrave-Macmillan.

Ó Conaill, D. (2014). Ontic structural realism and concrete objects. Philosophical Quarterly, 64(255), 284-300.

Ó Conaill, D. (2018). 'Grounding, physicalism and necessity. Inquiry, 61(7), 713-730.

Oderberg, D. (2007). Real essentialism. London and New York: Routledge.

Peijnenburg, J., \& Atkinson, D. (2013). The emergence of justification. Philosophical Quarterly, 63(252), 546-564.

Plantinga, A. (1974). The nature of necessity. Oxford: Clarendon Press.

Putnam, H. (1975). The meaning of "meaning". Minnesota Studies in the Philosophy of Science, 7, 131-193.

Rabin, G. O., \& Rabern, B. (2016). Well founding grounding grounding. Journal of Philosophical Logic, 45(4), 349-379.

Railton, P. (1986). Moral realism. Philosophical Review, 95(2), 163-207.

Raven, M. J. (2013). Is ground a strict partial order? American Philosophical Quarterly, 50(2), 191-199.

Raven, M. J. (2015). Ground. Philosophy Compass, 10(5), 322-333.

Raven, M. J. (2016). Fundamentality without foundations. Philosophy and Phenomenological Research, 93(3), 607-626. 
Rodriguez-Pereyra, G. (2015). Grounding is not a strict order. Journal of the American Philosophical Association, 1(3), 517-534.

Rosen, G. (2010). Metaphysical dependence: Grounding and reduction. In B. Hale \& A. Hoffmann (Eds.), Modality: metaphysics, logic, and epistemology (pp. 109-136). Oxford: Oxford University Press.

Schaffer, J. (2009). On what grounds what. In D. Manley, D. J. Chalmers, \& R. Wasserman (Eds.), Metametaphysics: New essays on the foundations of ontology (pp. 347-383). Oxford: Oxford University Press.

Schaffer, J. (2010). Monism: The priority of the whole. Philosophical Review, 119(1), 31-76.

Schaffer, J. (2012). Grounding, transitivity, and contrastivity. In F. Correia \& B. Schnieder (Eds.), Metaphysical grounding: Understanding the structure of reality (pp. 122-138). Cambridge: Cambridge University Press.

Schaffer, J. (2017). The ground between the gaps. Philosophers' Imprint, 17(11), 1-26.

Schnieder, B. (2017). Grounding and dependence. Synthese. https://doi.org/10.1007/s11229-017-1378-z.

Sider, T. (2011). Writing the book of the world. Oxford: Oxford University Press.

Sirkel, R., \& Tahko, T. E. (Eds.) (2014). Aristotelian metaphysics: Essence and ground. Special Issue of Studia Philosophica Estonica 7(2), 1-218.

Skiles, A. (2015). Against grounding necessitarianism. Erkenntnis, 80(4), 717-751.

Tahko, T. E. (2013). Truth-grounding and transitivity. Thought, 2(4), 332-340.

Tahko, T. E. (2014). Boring infinite descent. Metaphilosophy, 45(2), 257-269.

Tahko, T. E. (2018). Fundamentality. In E. N. Zalta (Ed.), The stanford encyclopedia of philosophy (Fall 2018 Edition). https://plato.stanford.edu/archives/fall2018/entries/fundamentality/.

Tahko, T. E., \& Lowe, E. J. (2015). Ontological dependence. In E. N. Zalta (Ed.), The stanford encyclopedia of philosophy (Spring 2015 Edition), http://plato.stanford.edu/archives/spr2015/entries/dependenceontological/.

Tallant, J. (2015). Ontological dependence in a space-time world. Philosophical Studies, 172(11), 3101-3118.

Thompson, N. (2016). Metaphysical interdependence. In M. Jago (Ed.), Reality making (pp. 38-55). Oxford: Oxford University Press.

Tiehen, J. (2015). Explaining causal closure. Philosophical Studies, 172(9), 2405-2425.

Toppinen, T. (2018). Essentially grounded non-naturalism and normative supervenience. Topoi, 37(4), $645-653$.

Trogdon, K. (2017). Revelation and physicalism. Synthese, 194(7), 2345-2366.

van Inwagen, P. (1998). Modal epistemology. Philosophical Studies, 92(1), 67-84.

Väyrynen, P. (2013). Grounding and normative explanation. The Aristotelian Society Supplementary, 87(1), $155-178$.

Vetter, B. (2011). Recent work: Modality without possible worlds. Analysis, 71(4), 742-754.

Vetter, B. (2015). Potentiality: From dispositions to modality. Oxford: Oxford University Press.

Wildman, N. (2013). Modality, sparsity and essence. The Philosophical Quarterly, 63(253), 760-782.

Wilson, J. (2018). Grounding-based formulations of physicalism. Topoi, 37(3), 495-512.

Wolff, J. (2012). Do objects depend on structures? British Journal for the Philosophy of Science, 63(3), $607-625$.

Yates, D. (2015). Dispositionalism and the modal operators. Philosophy and Phenomenological Research, 91(2), 411-424.

Zalta, E. N. (2006). Essence and modality. Mind, 115(459), 659-694.

Publisher's Note Springer Nature remains neutral with regard to jurisdictional claims in published maps and institutional affiliations. 